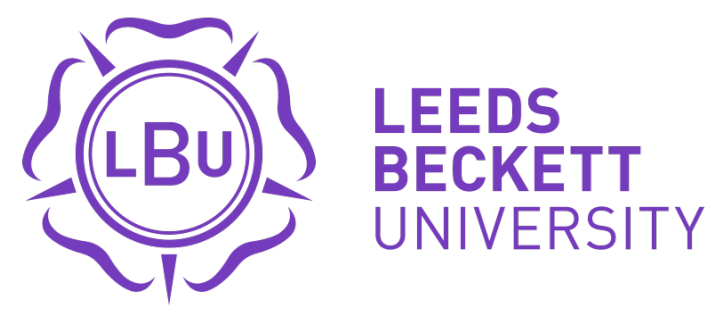

Citation:

Banerjee, S and Deng, $\mathrm{J}$ and Gorse, $\mathrm{C}$ and Vajpayee, $\mathrm{V}$ and Becerra, VM and Bausch, $\mathrm{N}$ and Shimjith, SR and Arul, J (2020) ANN Based Sensor and Actuator Fault Detection in Nuclear Reactors. In: 2020 The 8th International Conference on Control, Mechatronics and Automation (ICCMA). IEEE. ISBN 978-1-7281-9210-9 DOI: https://doi.org/10.1109/ICCMA51325.2020.9301579

Link to Leeds Beckett Repository record:

https://eprints.leedsbeckett.ac.uk/id/eprint/7193/

Document Version:

Book Section (Accepted Version)

(C) 2020 IEEE. Personal use of this material is permitted. Permission from IEEE must be obtained for all other uses, in any current or future media, including reprinting/republishing this material for advertising or promotional purposes, creating new collective works, for resale or redistribution to servers or lists, or reuse of any copyrighted component of this work in other works.

The aim of the Leeds Beckett Repository is to provide open access to our research, as required by funder policies and permitted by publishers and copyright law.

The Leeds Beckett repository holds a wide range of publications, each of which has been checked for copyright and the relevant embargo period has been applied by the Research Services team.

We operate on a standard take-down policy. If you are the author or publisher of an output and you would like it removed from the repository, please contact us and we will investigate on a case-by-case basis.

Each thesis in the repository has been cleared where necessary by the author for third party copyright. If you would like a thesis to be removed from the repository or believe there is an issue with copyright, please contact us on openaccess@leedsbeckett.ac.uk and we will investigate on a case-by-case basis. 


\title{
ANN Based Sensor and Actuator Fault Detection in Nuclear Reactors
}

\author{
Shohan Banerjee, Jiamei Deng ${ }^{1}$, Chris Gorse ${ }^{1}$, Vineet Vajpayee ${ }^{2}$, Victor M. Becerra ${ }^{2}$, Nils Bausch ${ }^{2}$, \\ S.R. Shimjith ${ }^{3}$ and A. John Arul ${ }^{4}$
}

\begin{abstract}
In the nuclear power plants (NPPs), fault detection and diagnosis (FDD) methods are very important to improve the safety and reliability of plants. Researchers have established various FDD methods such as, model-based methods, data-driven methods, and signal-based methods. In practical applications model-based methods are very difficult to achieve. Thus, various data-driven methods and signal-based methods have been applied for monitoring key subsystems in NPPs. In this paper a brief overview of Artificial Neural Network (ANN) based FDD method is presented. Simulated data have been generated to train the ANNs as per requirement and to compare with the plant signal during fault. A technique has been proposed analyzing two sensors data (power sensor and coolant sensor) to determine the sensor and actuator fault in closed loop in presence of robust (Proportional-Integral-Derivative) PID controller. Results are produced with credible MATLAB simulation.
\end{abstract}

\section{Index Terms- ANN, Fault Detection, NPP, PWR}

\section{INTRODUCTION}

A Nuclear Power Plant (NPP) is a highly complex process plant where a number of sensors and actuators are used to monitor and control different parameters, respectively. However, sensors and actuators endure various faults such as component failure and variations in operating conditions over time due to their inner structural modifications which leads to precision degradation of measurement and efficiency of plants. Therefore, reliable functioning of sensors and actuators is crucial for optimal process control. To maintain high level of performance of NPPs, it is necessary to detect and diagnose faults promptly so that corrective action can be taken to accommodate the system alternation to prevent the certain shutdown or any big accidental scenario [1].

Over the past decades, researchers have devoted them to fault detection and isolation modelling. Many methods for faults detection and isolation have already been established. Model based fault detection is extremely popular among those methods. Raphaela et al. in [2] proposed a fault detection method based on physical redundancy where the output is compared with that of the redundant sensor. Gautam et al. in [3] has shown a statistical algorithm for time-varying incipient fault detection and isolation of sensors. Extended Kalman filter has been used here to formulate the fault detection index and fault signature.

${ }^{1}$ Jiamei Deng, and Chris Gorse are with School of Built Environment, Engineering and Computing, Leeds Beckett University, Leeds, UK, j.deng@leedsbeckett.ac.uk, c.gorse@leedsbeckett.ac.uk

${ }^{2}$ Vineet Vajpayee, Victor M. Becerra, and Nils Bausch are with School of Energy and Electronic Engineering University of Portsmouth, UK,vineet.vajpayee@,victor.becerra@,nils.bausch@port.ac.uk

${ }^{3}$ S.R. Shimjith is with Reactor Control System Design Section, Bhabha Atomic Research Centre, Mumbai, India, srshim@barc.gov.in

${ }^{4}$ John Arul is with Reactor Shielding and Data Division, Indira Gandhi Centre for Atomic Research, Kalpakkam, India, arul@igcar.gov.in
Another technique proposed by Zhao et al. in [4] is based on an integrated approach to detect and isolate the fault of the field devices like sensors, actuators, controllers in NPPs. With this procedure, nuclear plants are described as a causal graph where individual process variable is in connection with adaptive fuzzy inference system models. Support vector machine and improved particle swarm optimization (PSO) have been applied for hybrid fault diagnosis in [5]. Ma et al. [6] has published a review on applications of fault detection and diagnosis methods on NPPs. Effectiveness of fault tolerant techniques in digital instruments was studied in [7]. Chao et al. [8] has combined deep neural networks with system performance models for hybrid deep fault detection and isolation. An improved Principal Component Analysis (PCA) method for detecting and isolating sensor faults in a NPP has been proposed in [9]. Mandal et al. [10] has proposed a statistical method for fault detection and isolation where an enhanced reconstruction method is presented using Enhanced Singular Value Decomposition (ESVD) for a Fast Breeder Test Reactor (FBTR).

ANN is capable of solving nonlinear problems and hence it can be used effectively in fault detection and classification [11]. ANN is widely accepted and it has following features:

1) ANN can predict fast, reliably, and accuratly depending on the training, because its working depends upon a series of very simple operations.

2) The nature of the nuclear reactor system changes with disturbances. Hence a neural network can incorporate the dynamic changes in the reactor systems.

Artificial Neural network (ANN) based fault detection technique for nuclear reactors has been proposed by Hwang et al. [11] and Elnokity et al. [12]. However, this technique deals mainly with sensor faults.

In this paper, a fault detection technique of power sensors, coolant temperature sensors and actuators (control rod) has been established by analyzing only two sensor data in closed loop in presence of a robust PID controller. The fault detection problem becomes more challenging due to the robust PID controller, which can reject disturbances and has good tracking capability.

The remainder of the paper is organized as follows: Section II describes a Pressurized Water Reactor (PWR) type of NPPs. In Section III, details of ANN, data generation, training and detection technique are established. Section IV presents the credible MATLAB simulation for three cases: power sensor fault, coolant temperature sensor fault and actuator fault. Finally, Section IV concludes this work.

\section{PWR WITH THERMAL HYDRAULIC MODEL}

In this section, it is attempted to obtain an interval state space model for a PWR. A normalized point kinetic model of a PWR has been considered with a thermal hydraulic model. The 
Xenon and Iodine dynamics are of less consequence during total power control, so they are not considered here.

The dynamic model is given by:

$$
\frac{d P}{d t}=\frac{\rho_{t}-\beta}{\Lambda} P+\sum_{i=1}^{6} \lambda_{i} C_{i}
$$

where $\beta=\sum_{i=1}^{6} \beta_{i}$

$$
\frac{d C_{i}}{d t}=\beta_{i} \frac{P}{\Lambda}-\lambda_{i} C_{i}
$$

where $P$ is neutronic power, $\rho_{t}$ is total reactivity, $\Lambda$ is neutron generation time, $\lambda_{i}, \beta_{i}$, and $C_{i}$ are decay constant, fraction of delayed neutrons, and delayed neutron precursors' concentration of $i^{\text {th }}$ group, respectively.

The core thermal-hydraulics model is given by Mann's model [13] which considers two coolant lumps for every fuel lump,

$$
\begin{aligned}
& \frac{d T_{f}}{d t}=H_{f} P-\frac{1}{\tau_{f}}\left(T_{f}-T_{c 1}\right) \\
& \frac{d T_{c 1}}{d t}=\frac{1}{\tau_{c}}\left(T_{f}-T_{c 1}\right)-\frac{2}{\tau_{r}}\left(T_{c 1}-T_{c i n}\right) \\
& \frac{d T_{c 2}}{d t}=\frac{1}{\tau_{c}}\left(T_{f}-T_{c 1}\right)-\frac{2}{\tau_{r}}\left(T_{c 2}-T_{c 1}\right)
\end{aligned}
$$

where $T_{f}$ is average fuel temperature; $T_{c 1}$ and $T_{c 2}$ are average coolant temperatures in node 1 and node 2 , respectively; $T_{\text {cin }}$ is inlet temperatures of the first coolant node; $H_{f}$ characterizes the rate of rise of fuel temperatures; $\tau_{f}$ and $\tau_{c}$ are time constants representing mean time for heat transfer from fuel to coolant and from core outlet to inlet, respectively while $\tau_{r}$ represents coolant residence time in the core. The heat transfer coefficient from fuel to coolant is assumed to be constant.

In this paper only the power control loop without secondary side coolant heat transfer has been considered. The change in total reactivity is considered due to the control rod movement and reactivity feedback due to fuel and coolant temperature. Here, a control rod acts as an actuator and this actuator movement can be represented by:

$$
\frac{d \rho_{e x}}{d t}=G z
$$

where $\rho_{e x}$ is the external reactivity injected to the reactor core due to the control rod movement, $G$ is the reactivity worth of control rod while $z$ is the speed of the control rod movement. The total reactivity can be obtained by:

$$
\rho_{t}=\rho_{e x}+\alpha_{f} T_{f}+\alpha_{c} T_{c 1}+\alpha_{c} T_{c 2}
$$

where, $\alpha_{f}$ and $\alpha_{c}$ represent the temperature coefficients of reactivity due to fuel and coolant, respectively. Then (1)-(7) have been used to develop a nonlinear model of PWR. In this case itis assumed that, the input variable is controlling rod speed and the output variables are reactor power and coolant average temperature. In this paper, avoiding the detailed design of the sensor, sensor gain has been incorporated to the system, which is assumed to be linear for corresponding output. Next section will describe the procedure of the fault detection modeling.

\section{FAUlt DETECTION MODELLING}

ANN has powerful non-linear mapping properties, noise tolerance, self-learning and parallel processing capabilities which add an important feature of a neural network used for prediction or estimation. It will also learn the dynamics of the system either to be linear or non-linear dynamic behaviour during the learning session made over several learning cycles.

\section{a. Structure of ANN}

In this case, two networks are required as shown in table1 and every network is built with two-layer feed-forward networks with sigmoid hidden neurons and linear output neurons. For the given consistent data and enough neurons in its hidden layer, this structure can fit multi-dimensional mapping problems.

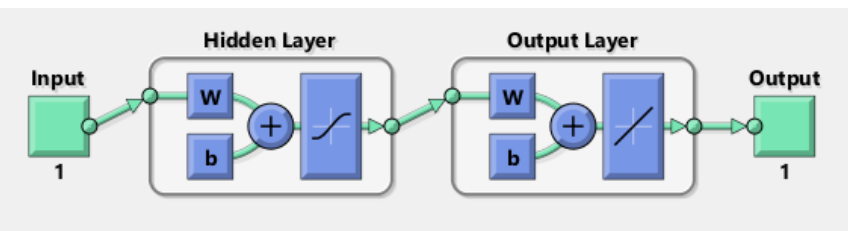

Fig.1 Structure of Neural Network (NN)

Fig. 1 describes the structure of the each NN. The number of neurons in hidden layer for each network is different and it has been chosen by several runs of trial and error procedure and the best result has been taken for training. Table 1 shows the details of the network.

\section{b. Data generation and training:}

For ANN based fault detection, fault free input and output data are required for training purpose of ANN. The training data sets have been generated from the system simulation model described in section II, rather than actual operational plant data.

TABLE I. DifFERENT NETWORK STRUCTURE

\begin{tabular}{|l|l|l|l|l|}
\hline Network & Input & $\begin{array}{l}\text { Hidden } \\
\text { Layer }\end{array}$ & $\begin{array}{l}\text { Output } \\
\text { Layer }\end{array}$ & Output \\
\hline NN1 & $\begin{array}{l}\text { Normalised } \\
\text { demand power } \\
(\mathrm{X} 1)\end{array}$ & 5 & 1 & $\begin{array}{l}\text { Reactor } \\
\text { Power (Y1) }\end{array}$ \\
\hline NN2 & $\begin{array}{l}\text { Normalised } \\
\text { demand power } \\
(\mathrm{X} 1)\end{array}$ & 6 & 1 & $\begin{array}{l}\text { Coolant } \\
\text { Temperature } \\
\text { (Y2) }\end{array}$ \\
\hline
\end{tabular}




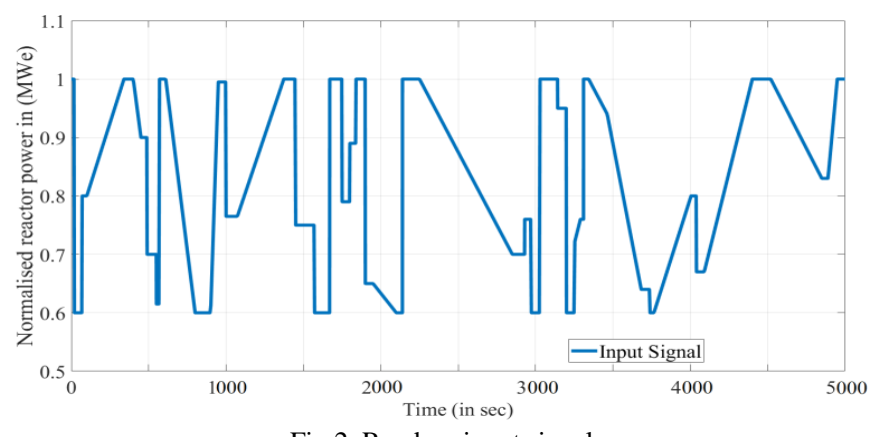

Fig.2. Random input signal

Fig 2 depicts the random different combinations of demand power which is used as an input data for the reactor system. Here, the power change has been considered within the range of $60 \%$ Full Power (FP) - 100\%FP for 5000 seconds with different pattern and magnitude between above range as shown in Fig.2. Next, the reactor model has been simulated without any fault with this random demand power described above. In this case, it has also been considered that a robust PID controller as described in [14] is working with the reactor model. The reactor output power (Y1) and the coolant temperature (Y2), corresponding to this input signal (X1), have been generated and stored in MATLAB workspace.

The networks are trained to adjust the weights to minimize the performance function. The gradient of the performance is determined using Levenberg-Marquardt (LM) back propagation technique which involves performing computations backward through the network. Mean Square Error (MSE) and Regression analysis (R) are used to test the performance. The average squared difference between outputs and targets is called MSE, lower values are better and zero means no error. The correlation between outputs and targets is measured by $R$ values. $R$ value $=1$ means a close relationship while the same of 0 indicates a random relationship. The LM algorithm is the most used for adjustment of the parameters of the Multi-Layer Perceptron neural networks.
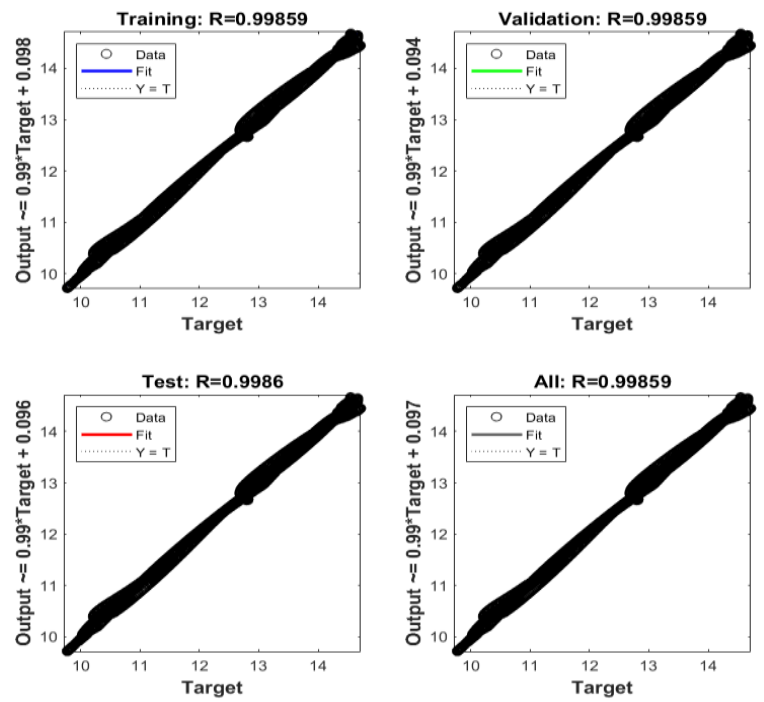

Fig.3. Regression analysis of NN1.

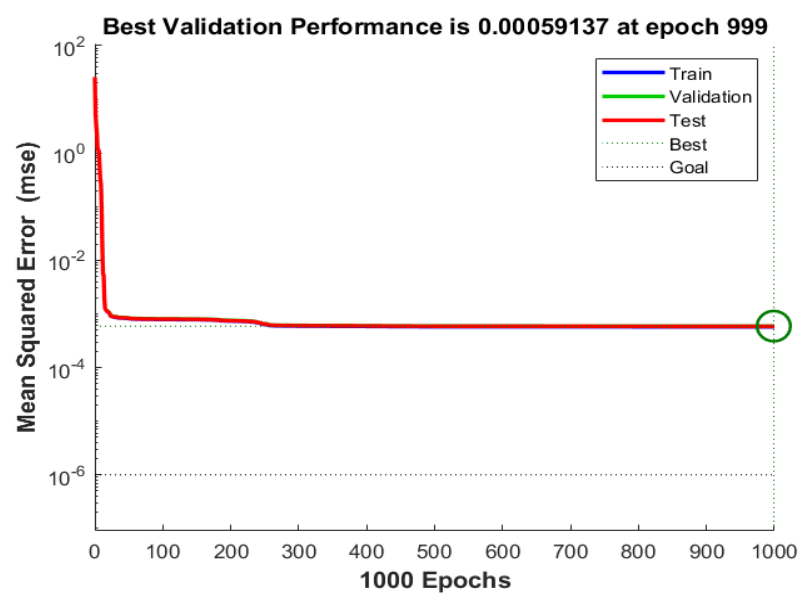

Fig.4. Performance analysis of NN1 using MSE.

The training response curves of two networks are shown in Fig.3-Fig.6. ANN training response for NN1 has been shown in Fig. 3 and Fig. 4 while Fig.5 and Fig.6 are for the NN2. Fig.3 and Fig. 5 having four subplots represent the regression analysis during training at one epoch interval. Fig. 4 and Fig. 6 show the corresponding training performance. Those graphs depict that all networks have optimal successful results of training.
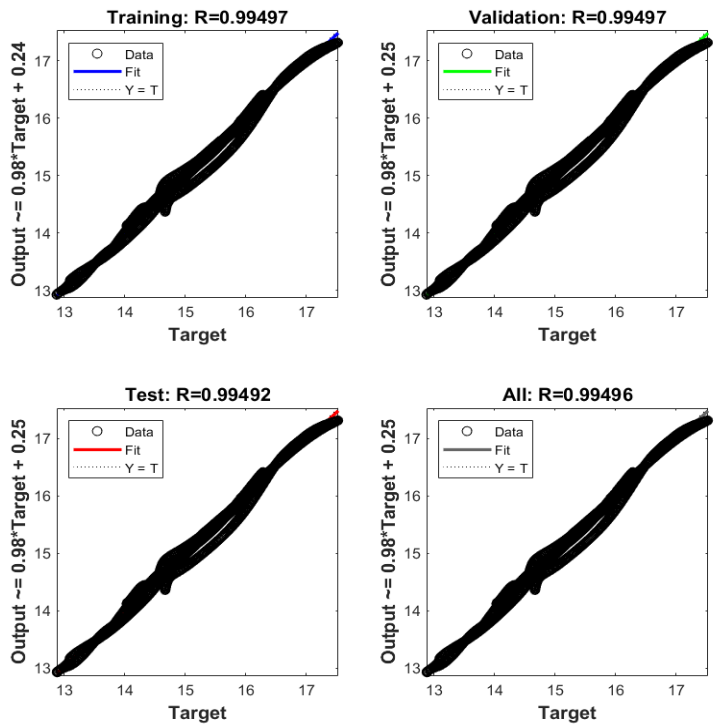

Fig. 5 Regression analysis of NN2.

Actual power sensor output and NN1 output have been compared and generated a percentage error $\left(e_{1}\right)$. Similarly, actual coolant sensor output has been compared with NN2 and generated a $\%$ error $\left(e_{2}\right)$. The comparisons of NN1 and NN2 with the corresponding actual outputs are shown in Fig.7 and Fig.8 respectively.

\section{c. Failure and detection technique}

In this work the sensor output of coolant temperature is not feedback to the reactor and only output from power sensor is 
considered for the feedback. Thus, during fault in the temperature sensor there is no variation in $e_{1}$. Only $e_{2}$ will

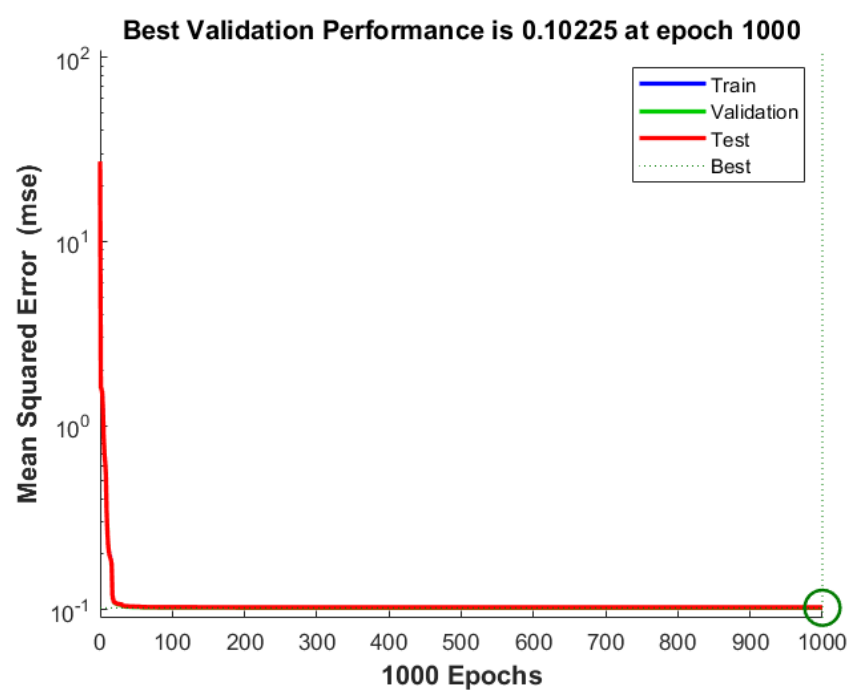

Fig.6. Performance analysis of NN2 using MSE

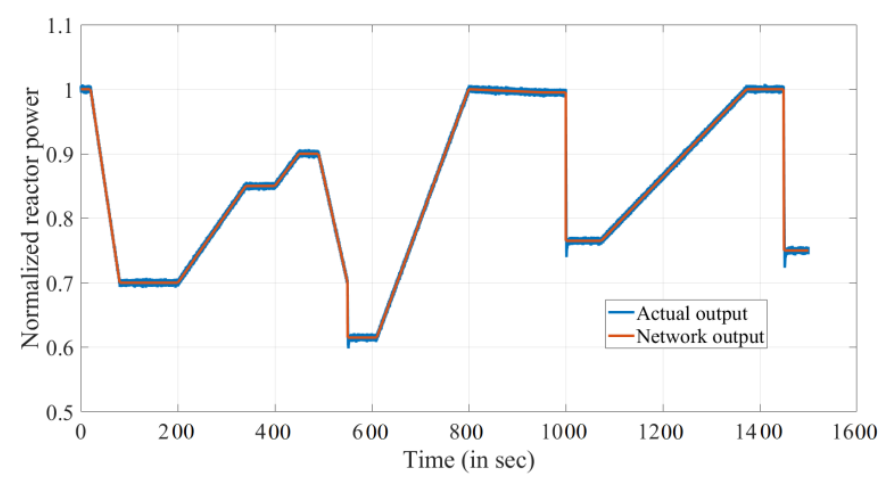

Fig.7. Network prediction with actual output with different data set of $\mathrm{NN} 1$

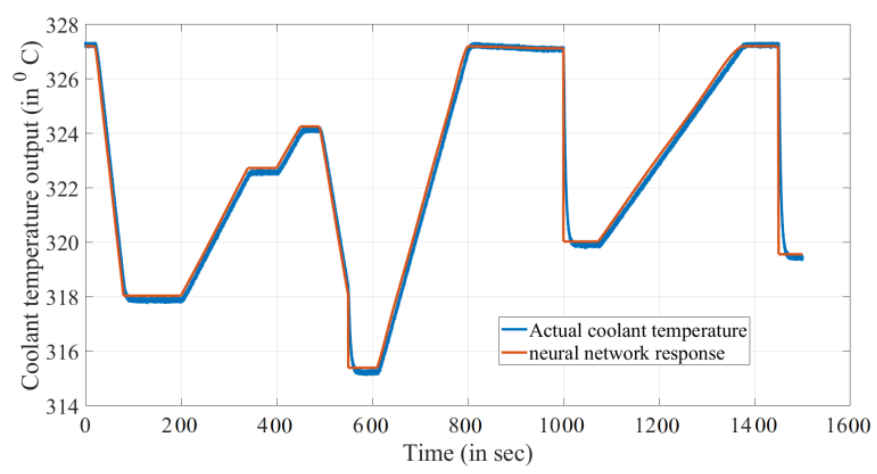

Fig.8. Network prediction with actual output with different data set of $\mathrm{NN} 2$

have a change in magnitude. But in case of power sensor failure, both $e_{1}$ and $e_{2}$ show a significant change. However, a PID controller in the closed loop will try to minimise $e_{1}$. As a result, in $e_{1}$ a sharp peak will appear while $e_{2}$ has a persistent value. In case of actuator saturation fault, the complete tracking is not possible so $e_{1}$ and $e_{2}$ both have a significant persistent value. $e_{1}$ and $e_{2}$ for all three faults have been shown in detail in Section IV in Fig.12-13, Fig.16-17 and Fig.20-21 respectively. This technique has been depicted in Fig.9 and used for the fault detection.

\section{SIMULATION AND RESULTS}

The trained ANNs based fault detection technique described in Section III is used to determine the faults in this section. In this paper three fault cases have been carried out.

\section{a. Case 1: Fault in temperature sensor}

First it is assumed that the reactor is running at $100 \% \mathrm{FP}$. After $60 \mathrm{sec}$ demand power is reduced to $80 \% \mathrm{FP}$ at $10 \% \mathrm{FP} / \mathrm{min} \mathrm{ramp}$. The controller for power loop is working well to handle this power manoeuvring. Then at $200 \mathrm{sec}$ a random fault in temperature sensor bias within limit $\pm 10 \%$ has been injected. Actual output power and coolant temperature has been shown in Fig.10 and Fig.11. Fig.12 and Fig.13 depict the error $e_{1}$ and $e_{2}$ respectively.

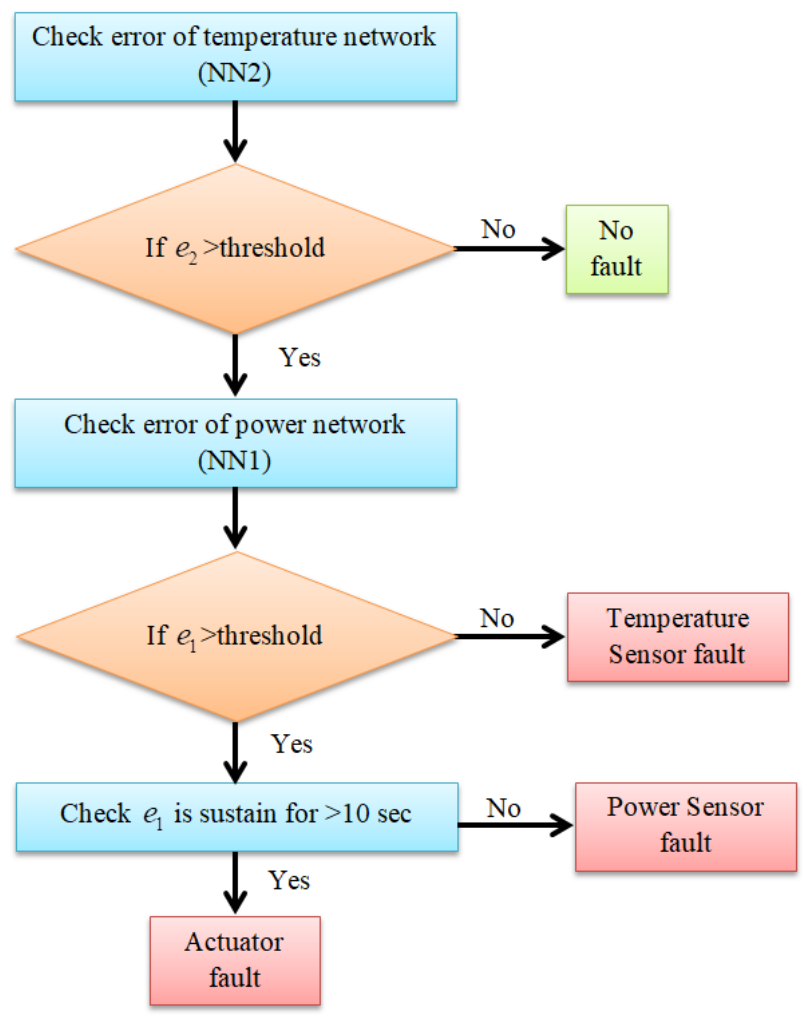

Fig.9. Flowchart for fault detection technique 


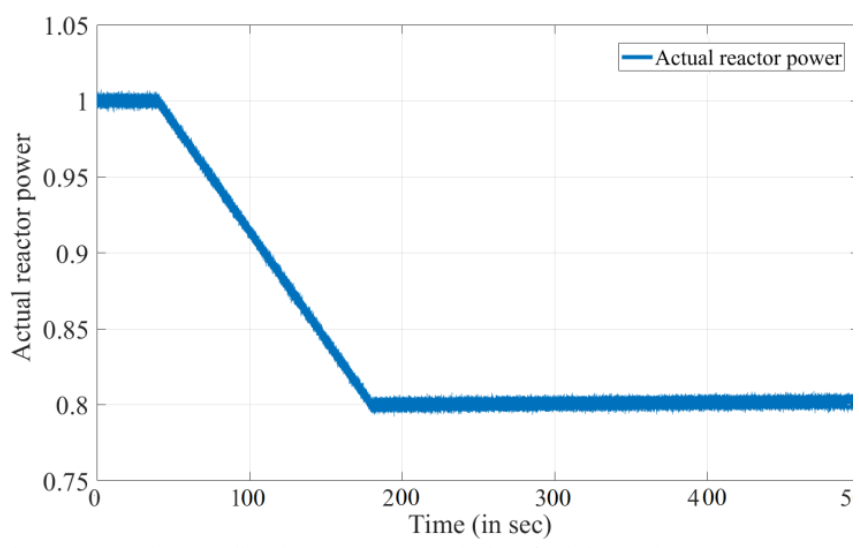

Fig.10. Actual normalized reactor power during fault in coolant temperature sensor.

As only reactor power is acting as a feedback element, so during fault in temperature sensor $e_{2}$ is not affecting the reactor power. So $e_{1}$ will remain in its tolerant limit, whereas $e_{2}$ has a persistent value as shown in Fig.12 and Fig.13. From Fig.9 it can be referred as a fault in temperature sensor.

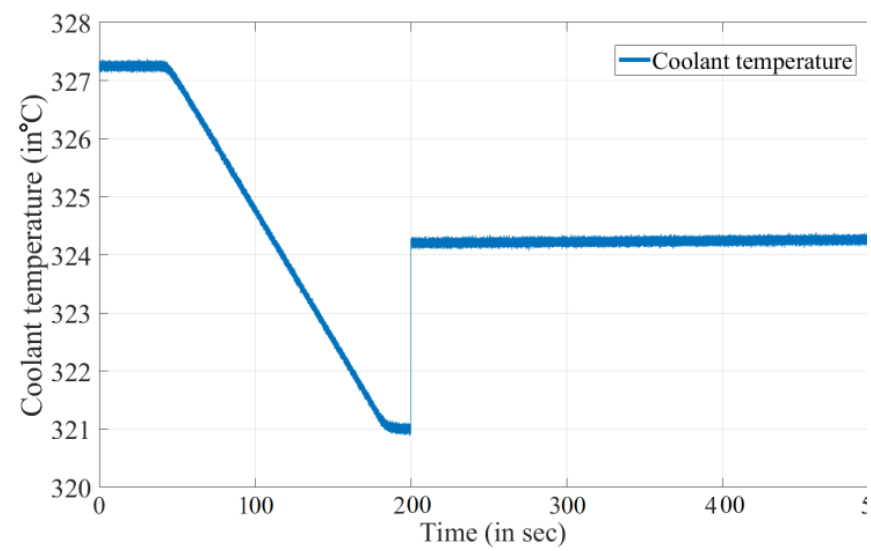

Fig.11. Actual coolant temperature during fault in coolant temperature sensor.

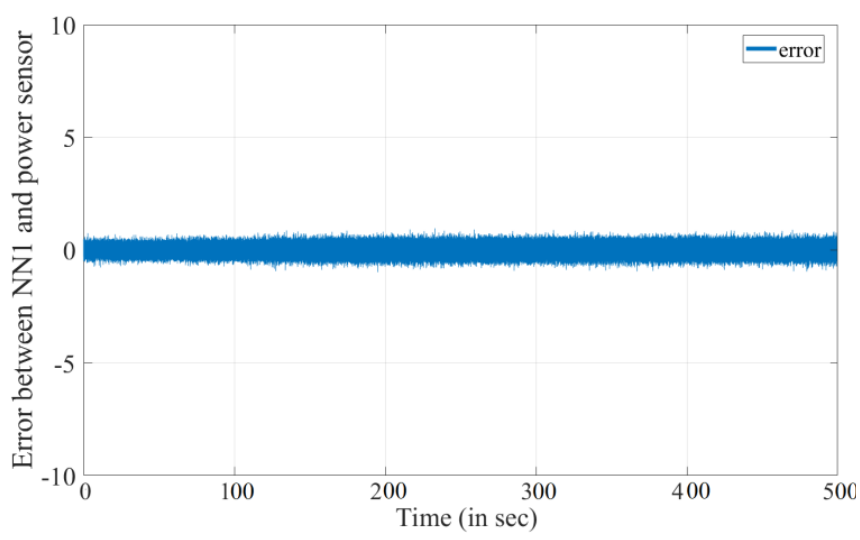

Fig.12. $e_{1}$ during fault in coolant temperature sensor.

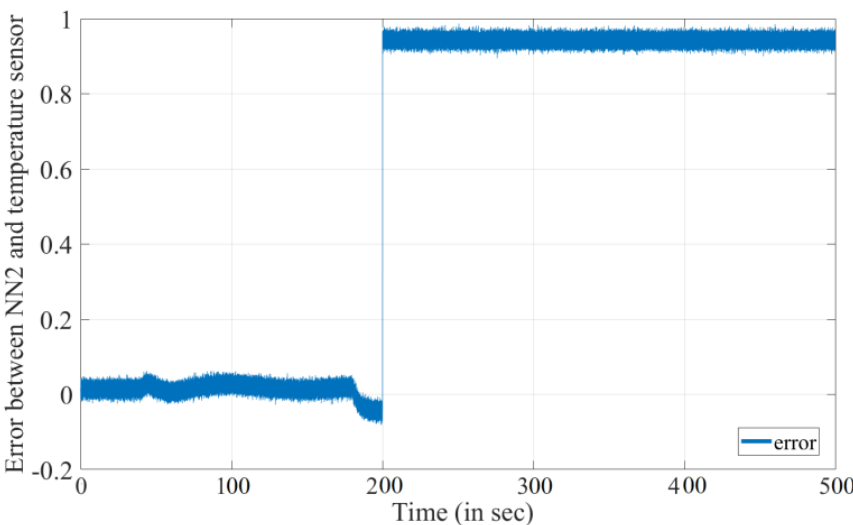

Fig.13. $e_{2}$ during fault in coolant temperature sensor.

\section{b. Case2: Fault in power sensor}

In this case, the initial condition of the reactor and the reduction of demand power scenario have been considered and are same with earlier ones. At $210 \mathrm{sec}$ a random bias fault having limit $\pm 5 \%$ has been injected. Corresponding actual reactor power, coolant temperature, $e_{1}$ and $e_{2}$ have been depicted in Fig.14-Fig.17 respectively.

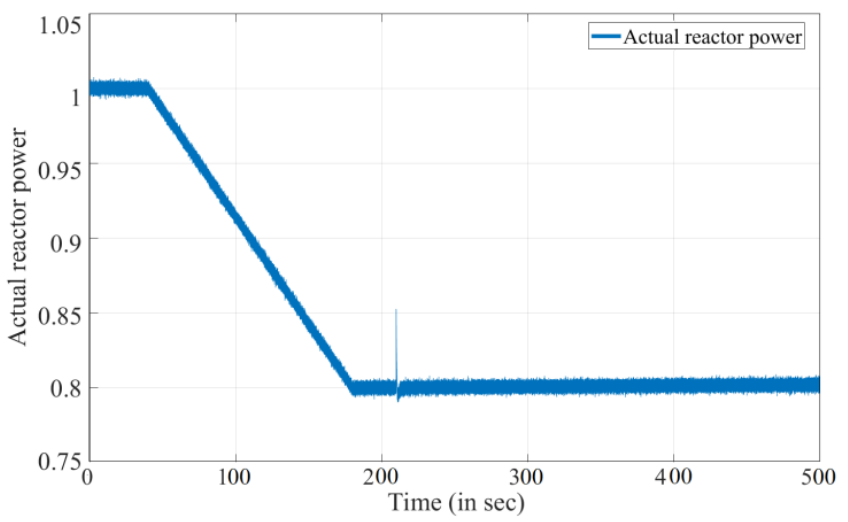

Fig.14. Actual normalised reactor power during fault in power sensor

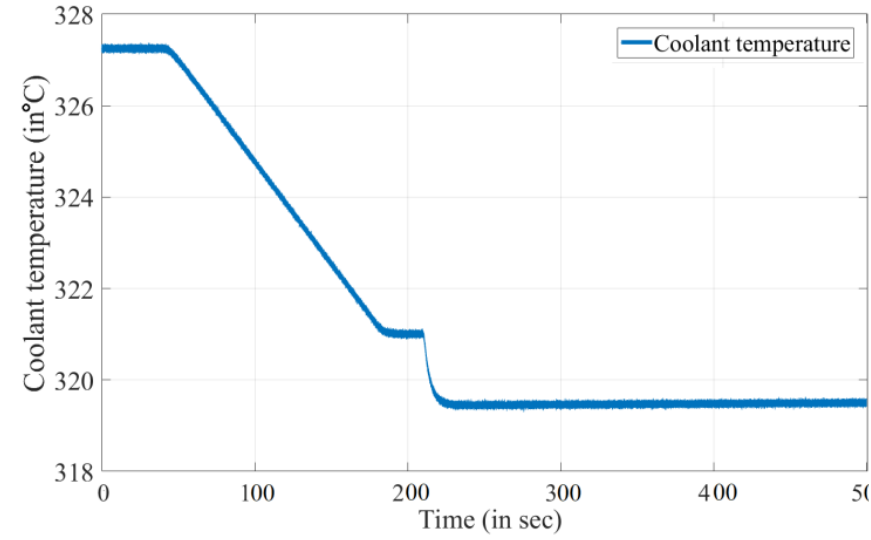

Fig.15. Actual coolant temperature during fault in power sensor 


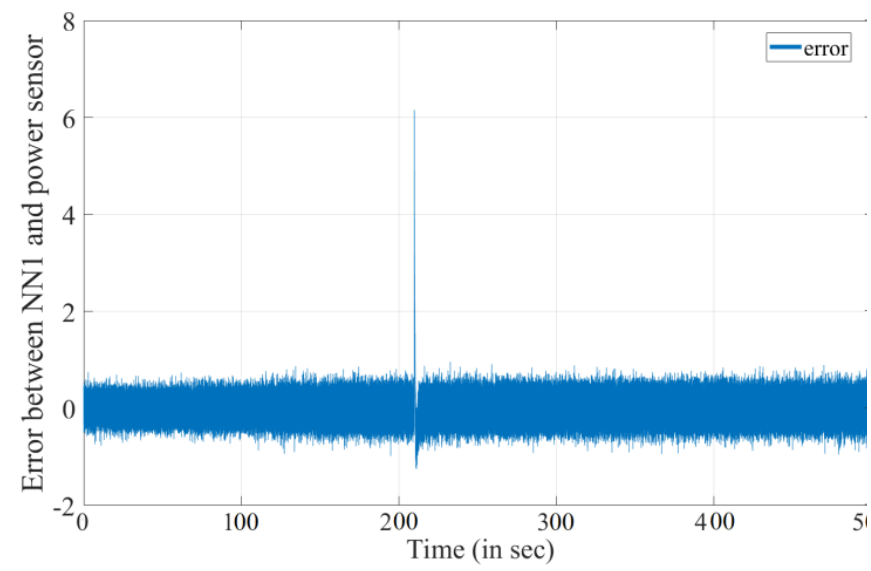

Fig.16. $e_{1}$ during fault in power sensor

As described in earlier section, output from power sensor is attached as a feedback connection. During a fault in power sensor, controller will try to track the reference signal which minimizes the process fault and $e_{1}$ as well. So, a peak will appear in $e_{1}$ as shown in Fig.14. Again, this peak may appear as a prediction error during transition period of fast ramping power maneuvering.

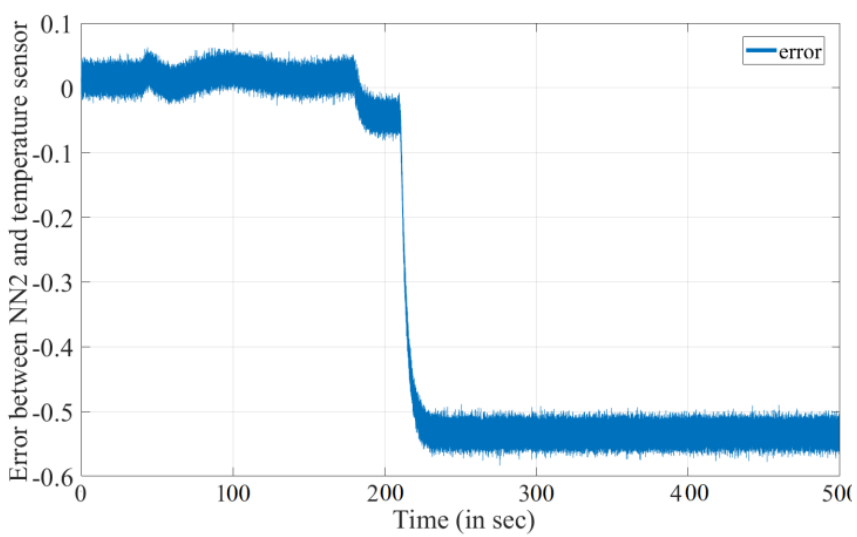

Fig.17. $e_{2}$ during fault in power sensor

To avoid this confusion, $e_{2}$ also is observed. If there is a fault in power sensor, the controller will try to minimise the error by introducing more positive or negative reactivity depending upon the direction of the fault which will ultimately affect the coolant temperature. Thus, there always a non-zero steady deviation will appear in $e_{2}$ as depicted in Fig.17. Owing to this situation it can be referred as a fault in power sensor.

\section{c. Case3: Fault in actuator (control rod)}

In this case, again it assumed that the reactor is running at $100 \% \mathrm{FP}$ and change in demand power is considered as earlier. During this transient it is assumed that control rod has been stuck in $90 \%$ of its actual position. Fig.18-Fig.21 depict the respective actual reactor power, coolant temperature, $e_{1}$ and $e_{2}$ respectively.

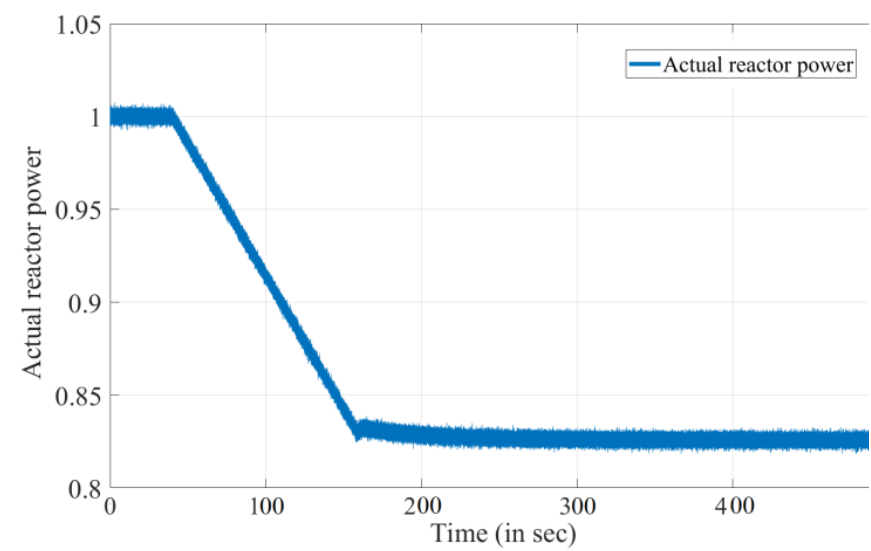

Fig.18. Actual normalized reactor power during fault in actuator.

In this case the actual reactor power could not reach to $80 \% \mathrm{FP}$ due to actuator saturation which will also affect the coolant temperature. Thus, in this case $e_{1}$ and $e_{2}$ both will have a significant persistent value as shown in Fig.20 and Fig.21. which only happens due to actuator fault.

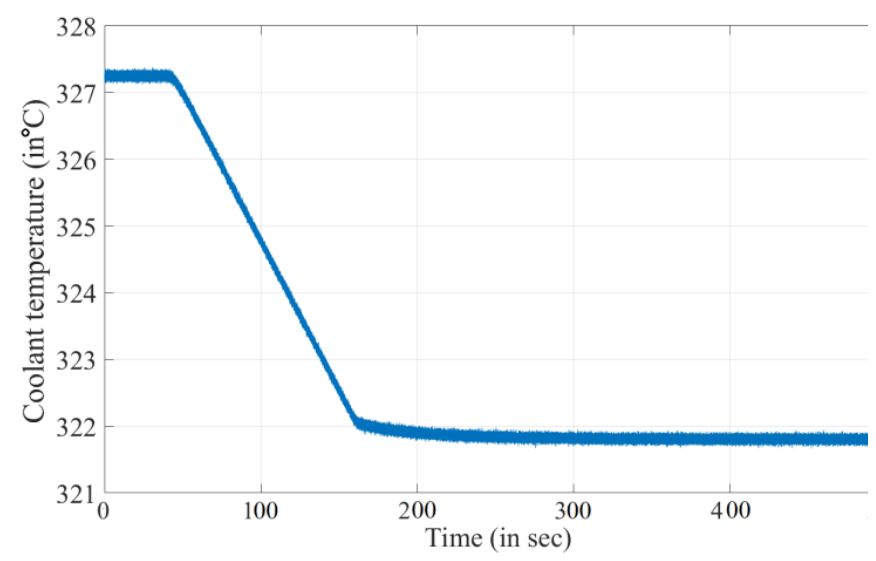

Fig.19. Actual coolant temperature during fault in actuator.

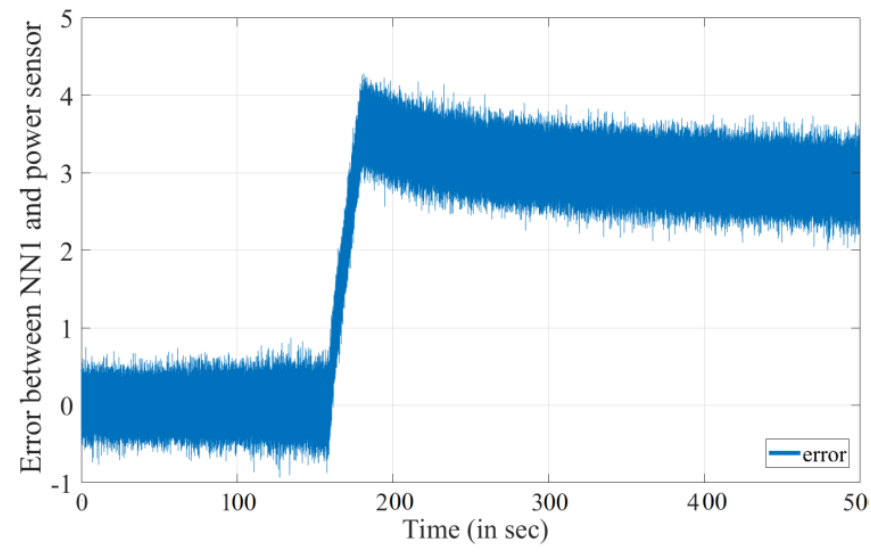

Fig.20. $e_{1}$ during fault in power actuator. 


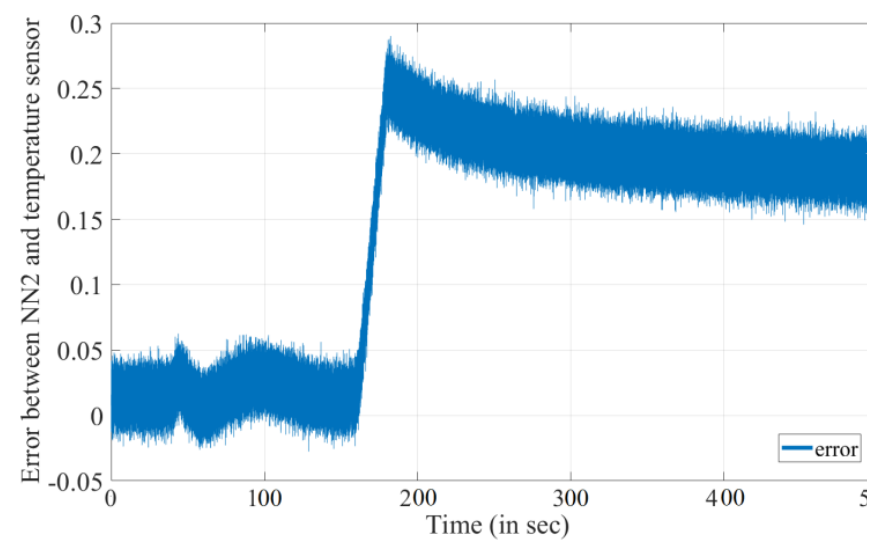

Fig.21. $e_{2}$ during fault in actuator.

\section{CONCLUSION}

In this work, fault detection in sensors and actuators of a PWR based NPP has been established only using the power sensor data and coolant sensor data. Well performing ANNs have been created for power sensors and coolant sensors. Three faults and their detection technique have been shown with a credible simulation. However, this methodology is tested with sensor bias fault only. As the sensor drift is a slow process it is a challenging task to apply this technique for detection of sensor drift. Further work can be carried out in that direction and isolation process.

\section{ACKNOWLEDGMENT}

The authors would like to thank The Engineering and Physical Sciences Research Council (EPSRC) for their financial support with References: EP/R021961/1, EP/M018717/1, and EP/R022062/1.

\section{REFERENCES}

[1]. Upadhyaya, B.R., Zhao, K. and Lu, B., "Fault monitoring of nuclear power plant sensors and field devices," Progress in Nuclear Energy, 2003, 43(1-4), pp.337-342.
[2]. Fernandes, R.G., Silva, D.R.C., de Oliveira, L.A.H.G. and Neto, A.D.D., "Faults detection and isolation based on neural networks applied to a levels control system," International Joint Conference on Neural Networks, 2007, August. (pp. 1859-1864). IEEE.

[3]. Gautam, S., Tamboli, P.K., Roy, K., Patankar, V.H. and Duttagupta, S.P., "Sensors incipient fault detection and isolation of nuclear power plant using extended Kalman filter and Kullback-Leibler divergence," ISA transactions, 2019, 92, pp.180-190.

[4]. Zhao, K. and Upadhyaya, B.R., "Adaptive fuzzy inference causal graph approach to fault detection and isolation of field devices in nuclear power plants," Progress in Nuclear Energy, 2005, 46(3-4), pp.226-240.

[5]. Wang, H., Peng, M.J., Hines, J.W., Zheng, G.Y., Liu, Y.K. and Upadhyaya, B.R., "A hybrid fault diagnosis methodology with support vector machine and improved particle swarm optimization for nuclear power plants," ISA transactions, 2019, 95, pp.358-371.

[6]. Ma, J. and Jiang, J., "Applications of fault detection and diagnosis methods in nuclear power plants: A review," Progress in nuclear energy, 2011, 53(3), pp.255-266

[7]. Kim, M.C., Seo, J., Jung, W., Choi, J.G., Kang, H.G. and Lee, S.J., "Evaluation of effectiveness of fault-tolerant techniques in a digital instrumentation and control system with a fault injection experiment," Nuclear Engineering and Technology, 2019, 51(3), pp.692-701.

[8]. Arias Chao, M., Kulkarni, C., Goebel, K. and Fink, O., "Hybrid deep fault detection and isolation: Combining deep neural networks and system performance models," International Journal of Prognostics and Health Management, 2019, 10(033).

[9]. Li, W., Peng, M. and Wang, Q., "Improved PCA method for sensor fault detection and isolation in a nuclear power plant," Nuclear Engineering and Technology, 2019, 51(1), pp.146-154.

[10]. Mandal, S., Santhi, B., Sridhar, S., Vinolia, K. and Swaminathan, P. "Sensor fault detection in Nuclear Power Plant using statistical methods," Nuclear Engineering and Design, 2017, 324, pp.103-110.

[11]. Hwang, B.C., Saif, M. and Jamshidi, M., "Neural based fault detection and identification for a nuclear reactor," IFAC Proceedings, 1993, Volumes, 26(2), pp.547-550.

[12]. Elnokity, O., Mahmoud, I.I., Refai, M.K. and Farahat, H.M., "ANN based sensor faults detection, isolation, and reading estimates-SFDIRE: applied in a nuclear process," Annals of Nuclear Energy, 2012. 49, pp.131-142.

[13]. Arda, S. E., and Holbert, K. E., "Nonlinear dynamic modeling and simulation of a passively cooled small modular reactor," Progress in Nuclear Energy, 2016, 91, pp. 116-131.

[14]. Banerjee, S., Deng, J., Vajpayee, V., Becerra, V.M., Bausch, N., Shimjith, S.R. and Arul, J., "LMI based robust PID controller design for PWR with bounded uncertainty using interval approach," In 2019 7th International Conference on Control, Mechatronics and Automation (ICCMA) (pp. 253-259), IEEE 